\title{
Dr. Luis Manuel Macías López (1943-2010) y las actividades académicas en la UAA
}

Departamento de Formación y Actualización Académica

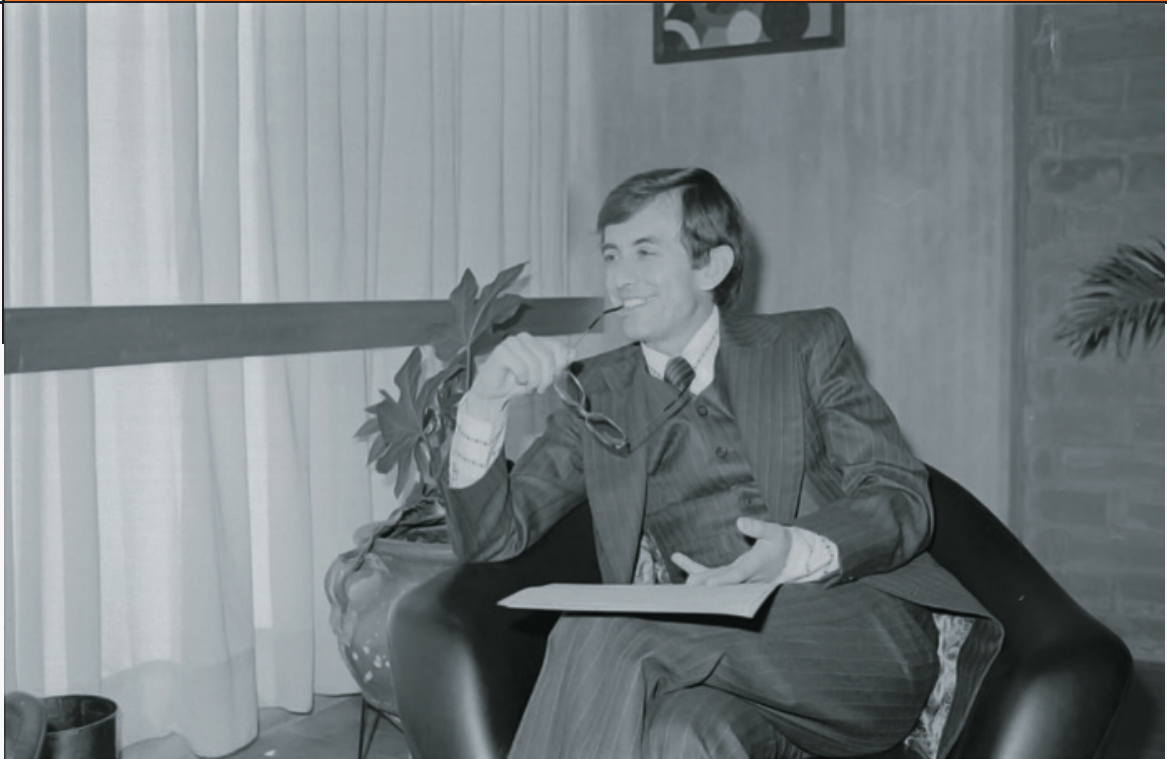

A

través de estas líneas, el Departamento de Formación y Actualización Académica, de la Dirección General de Docencia de Pregrado, de la Universidad Autónoma de Aguascalientes (UAA), desea presentar una breve síntesis de las actividades académicas desarrolladas en la UAA por el doctor Luis Manuel Macías López.

En 1974, ingresó como profesor a la UAA, impartiendo materias relacionadas con las ciencias del hombre en carreras como Arquitectura e Ingeniería Civil.

En virtud de su perfil, creó el Departamento de Asesoría Psicopedagógica y Orientación Vocacional, y fue jefe de los departamentos de Ciencias del Hombre, Psicología y Pedagogía (Saldívar, en Gallegos, 2013: 23). Asimismo, participó en la impartición de algunos cursos de formación docente que la UAA comenzó a ofrecer a sus profesores (Martínez, en Jiménez y Martínez, 2009: 86).

En 1978, coordinó los trabajos para la creación de la licenciatura en Ciencias y Técnicas de la Educación, la cual tuvo tres áreas de especialización: Consultor Psicólogo en el Campo de la Educación (actualmente Asesoría Psicopedagógica), Investigación Educativa, y Administración Educativa. 
De 1982 a 1993, fue director general de Asuntos Académicos ${ }^{1}$. Esta área institucional desarrollaba importantes funciones de apoyo académico, entre las que destacan: el diseño y actualización de planes de estudio, la formulación de las políticas de investigación, la planeación de actividades de extensión universitaria, y la evaluación del personal académico (UAA, 1980: 49-50).

Durante el periodo de gestión del doctor Luis Manuel Macías, integraron la dirección cinco departamentos administrativos: Apoyo a la Docencia e Intercambio Académico, Apoyo a la Investigación y Educación Continua, Apoyo a la Extensión, Asesoría Psicopedagógica y Orientación Vocacional, y Videoproducción Docente (UAA, 1982: 552), (UAA, 1985).

En la Dirección General de Asuntos Académicos, coordinó proyectos importantes, entre éstos sobresalen:

1. El diseño de 20 carreras a nivel licenciatura, aproximadamente, así como algunos programas de posgrado.

2. La integración de una metodología institucional para el diseño y revisión de planes de estudio.

3. El ingreso de la UAA al College Board de Puerto Rico, con lo cual se aplicó por varios años la Prueba de Aptitud Académica como examen de admisión en la institución.

4. Establecimiento de programas de asesoría a estudiantes.

5. Desarrollo de procesos para la evaluación de los profesores.

6. La incorporación de diversas instituciones educativas particulares a la UAA, específicamente de bachillerato.

7. El desarrollo de la extensión universitaria a través de una amplia gama de cursos dirigidos a la población en general (Gallegos et al., 2013).

En 1989, participó en la revisión del Diploma de Especialidad en Docencia, a partir de lo cual surgió el Programa de Formación de Profesores, mismo que fue revisado en 1995, que derivó en la elaboración del Programa de Formación Académica de Profesores (PFAP), colaborando decididamente en dicho proceso.

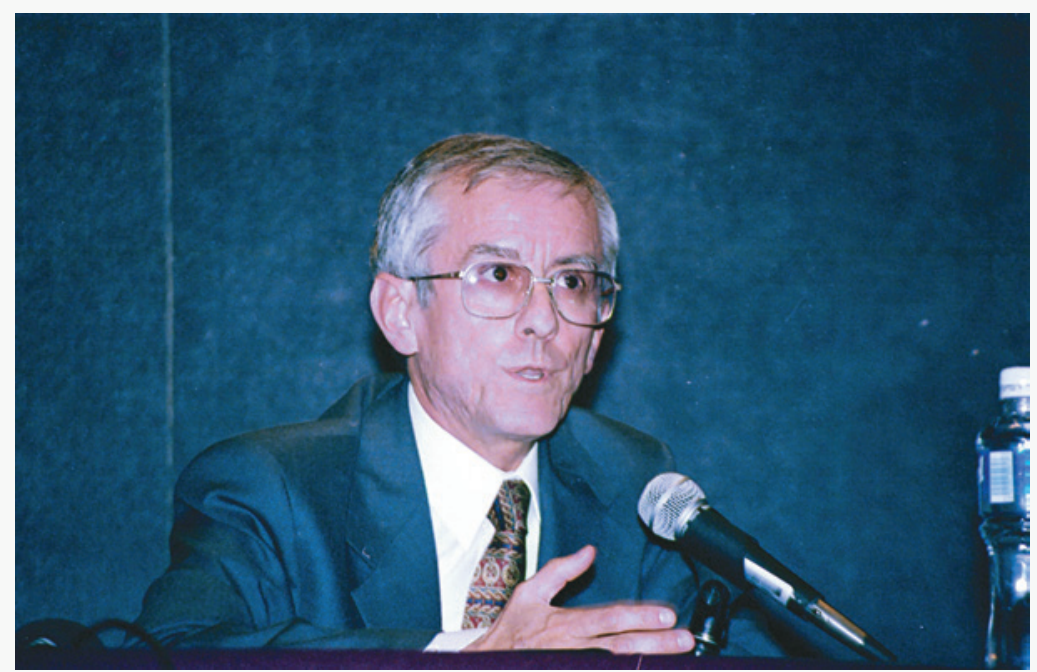

1 La Dirección General de Asuntos Académicos dio origen a las actuales direcciones generales de: Difusión y Vinculación, Docencia de Pregrado, Investigación y Posgrado, y Servicios Educativos. 
De 1996 a 2004, participó en el Equipo Coordinador del PFAP, en el cual desarrolló dos actividades principales: la asesoría psicológica a un gran número de personas que así lo solicitaron (personal de la UAA y público en general) y la impartición de los siguientes cursos de formación docente:

Curso

Periodo

Programa

Metodología

de la educación
Agosto-diciembre de 1983

Junio-septiembre de 1985
Diploma de Especialidad en Docencia

Conocimiento

y problemática

de los estudiantes

Agosto-diciembre de 1996

Agosto-diciembre de 1997

\begin{tabular}{cc}
\hline $\begin{array}{c}\text { El estudiante } \\
\text { y la influencia familiar }\end{array}$ & $\begin{array}{c}\text { Agosto-diciembre de 1997 } \\
\text { Agosto-diciembre de } 1998\end{array}$ \\
\hline $\begin{array}{c}\text { Teoría y práctica } \\
\text { de la asesoría estudiantil }\end{array}$ & $\begin{array}{c}\text { Febrero-junio de } 1998 \\
\text { Febrero-junio de } 1999\end{array}$ \\
\hline
\end{tabular}

Fuente: Departamento de Formación y Actualización Académica, 2015.

Como puede apreciarse, las aportaciones que el doctor Luis Manuel Macías López realizó al desarrollo académico de la UAA fueron diversas y significativas, tanto como director general de Asuntos Académicos, como profesor, jefe de departamento e integrante del Equipo Coordinador del Programa de Formación Académica de Profesores.

\section{Fuentes de consulta}

Gallegos, M. de L. (Comp.) (2013). Palabra de luz y fuego. La alegría santa de prodigarse: Luis Manuel Macías López. México: Colegio de Asesores Psicopedagógicos "Dr. Luis Manuel Macías López".

Jiménez, M. y Martínez, J. (Coords.) (2009). Testimonios docentes y la formación de profesores en la Universidad Autónoma de Aguascalientes. México: UAA.

Universidad Autónoma de Aguascalientes (1980). Ley Orgánica y Estatuto, en Correo Universitario, 18 de septiembre de 1980. México: UAA.

Universidad Autónoma de Aguascalientes (1982). Memoria 1978-1980. México: UAA.

Universidad Autónoma de Aguascalientes (1985). Carta de Organización aprobada por el H. Consejo Universitario el 11 de marzo de 1983, en Folleto de Información UAA 1985. México: UAA. 